\title{
When The Yankees Go Into Battle
}

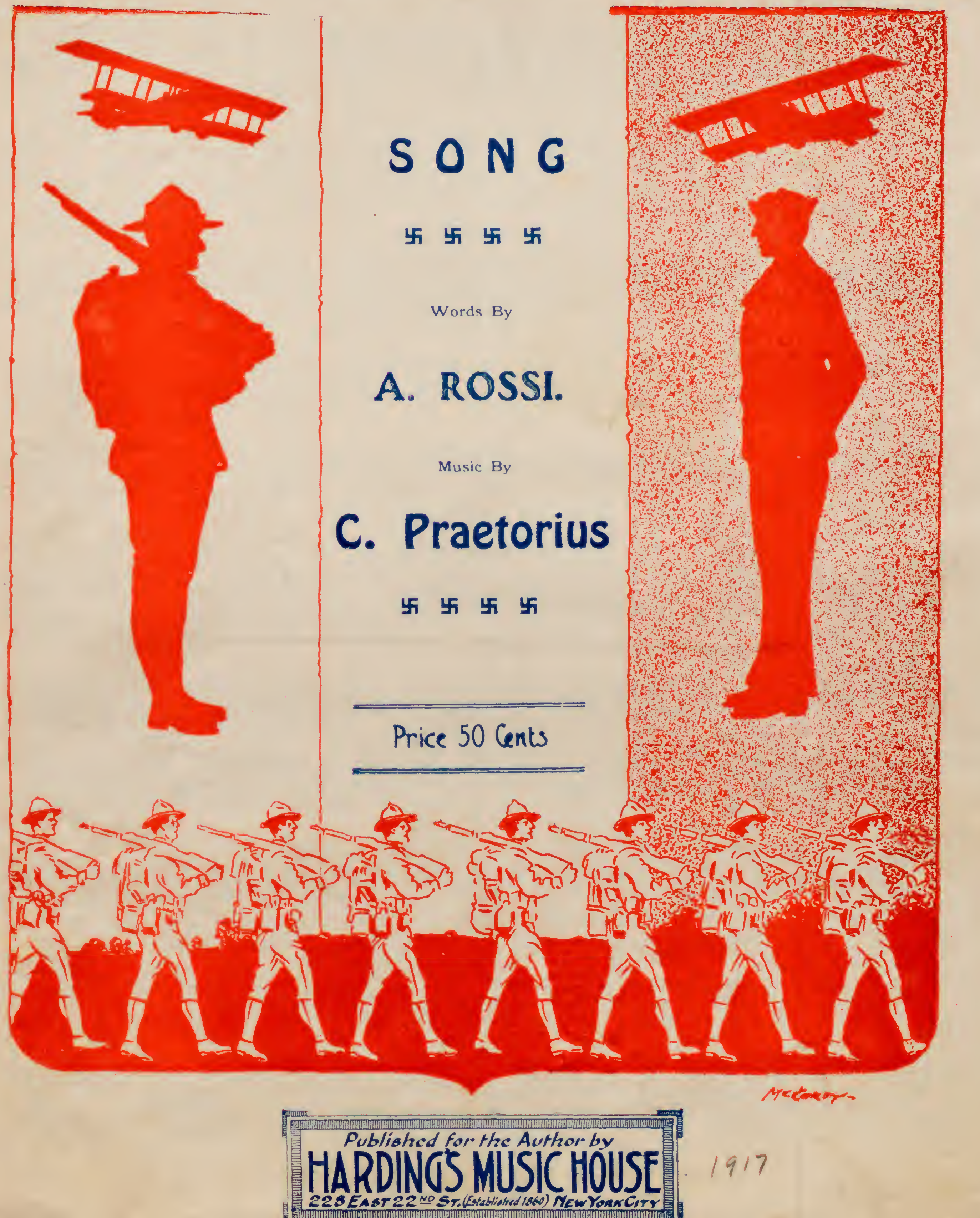




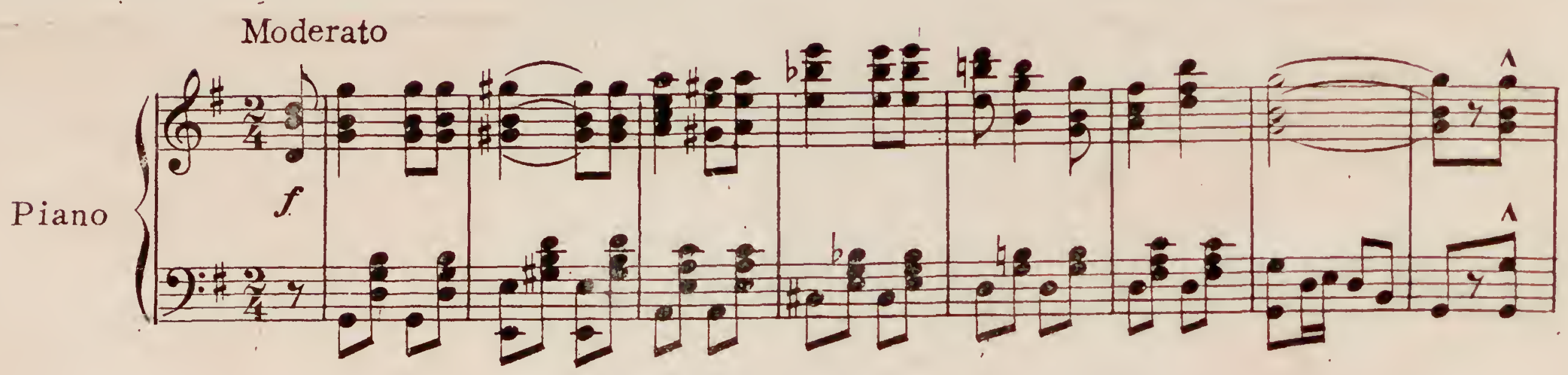

A mer-i-ca You're called to war - We_ are get-ting ready to go

A foreign foe _. in - vit - ed war_ And we will fight them on toe and toe__ A Yan-kee Doodle who
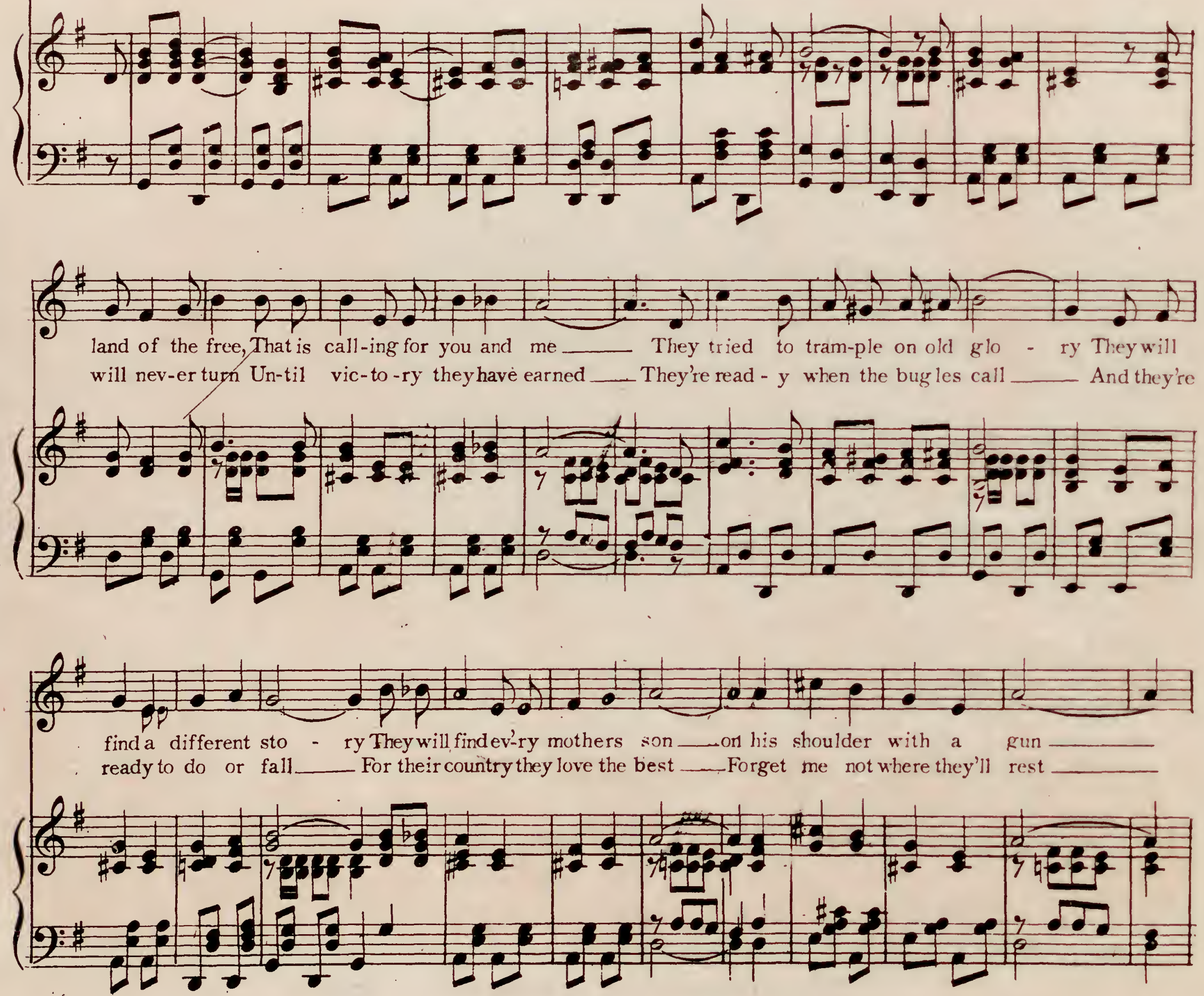


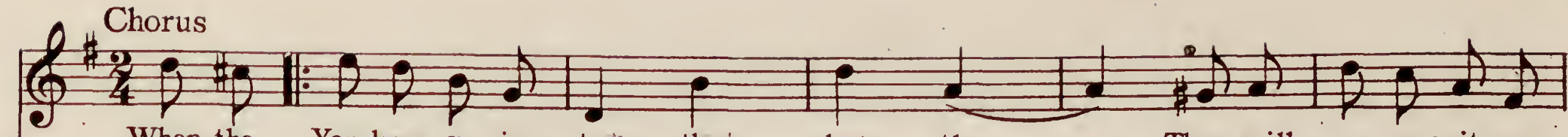

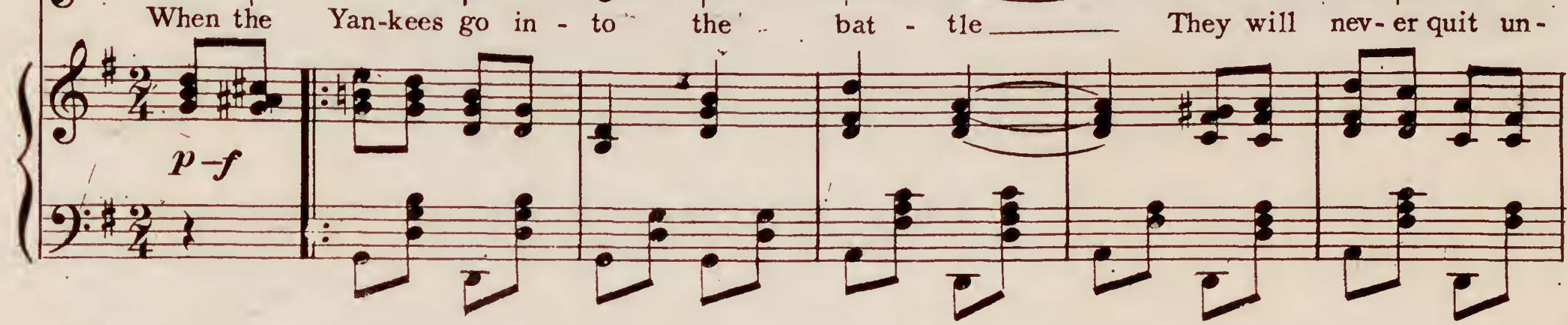

$f^{\sharp} \cdot$. . . . . . . ?

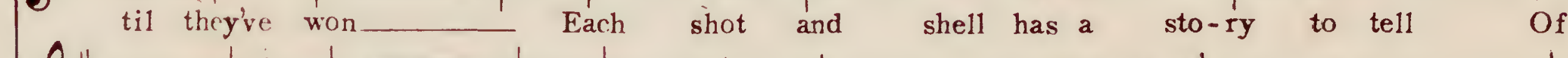

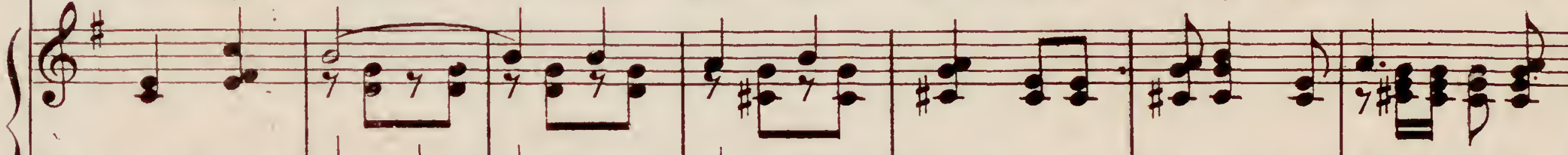

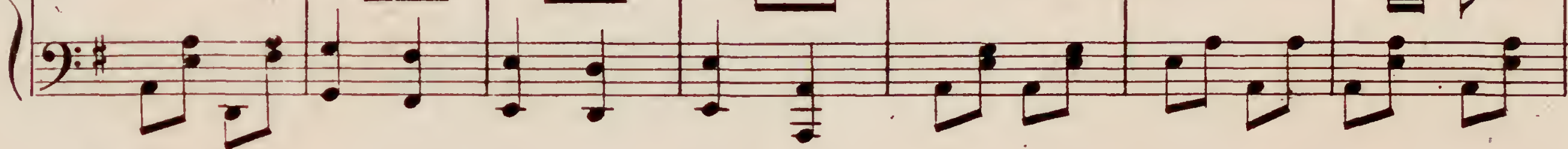

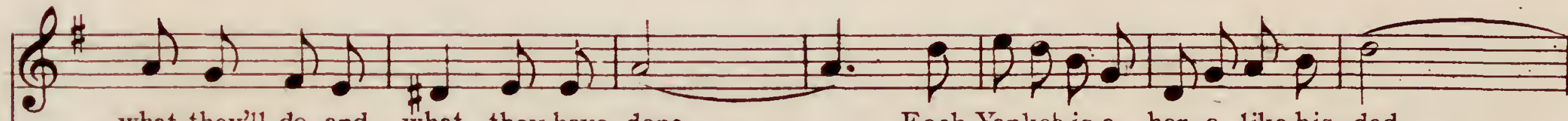

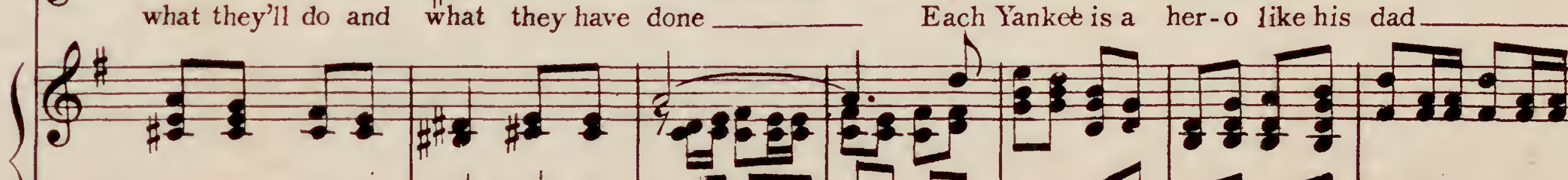

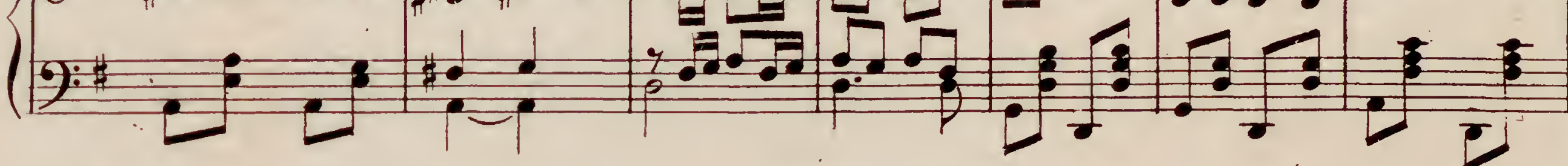

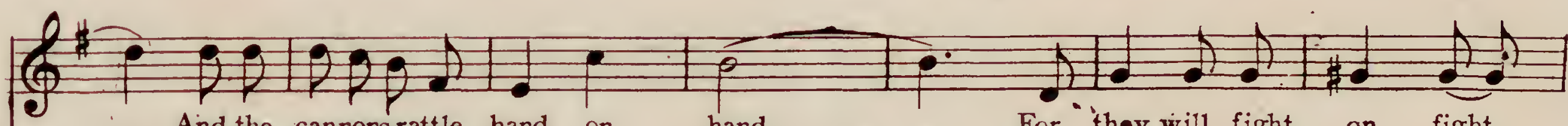

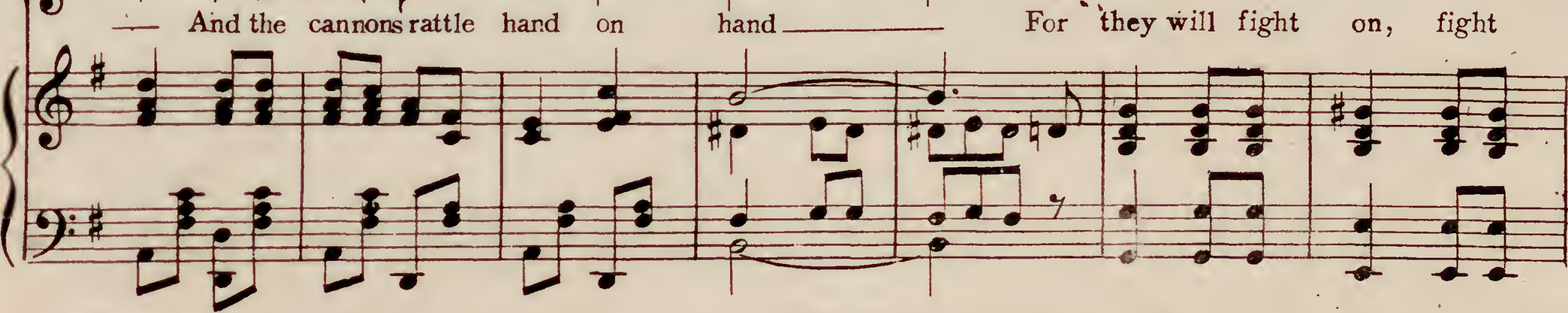

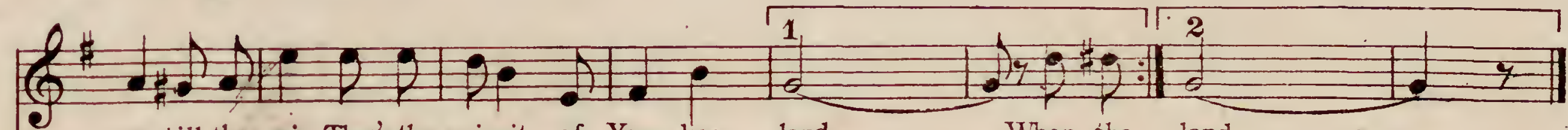

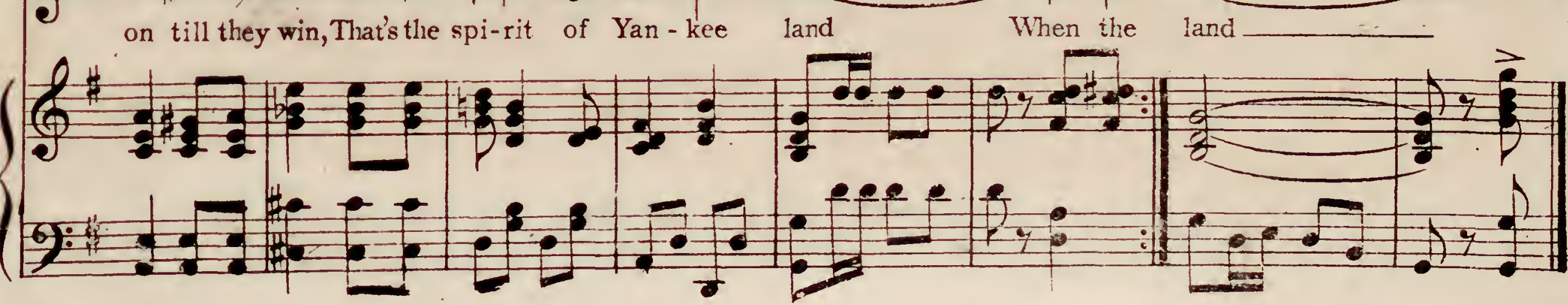


